\title{
Demystifying deliberate counterfeit purchase behaviour: Towards a unified conceptual framework
}

\author{
Piyush Sharma ${ }^{1}$ \\ Ricky Y. K. Chan ${ }^{2}$
}

\section{Brief Bios:}

Dr Piyush Sharma is a Professor in the School of Marketing at Curtin University in Perth, Australia. His research interests include services and international marketing, cross-cultural consumer behaviour, counterfeit purchase behaviour, self-regulation and self-regulatory failure. His research has been published in the Journal of International Business Studies, Journal of the Academy of Marketing Science, European Journal of Marketing, Journal of Service Research, Journal of Service Management, Journal of Services Marketing, Journal of Business Research, Marketing Intelligence \& Planning and Journal of Marketing Management, among others.

Dr Ricky Chan is an Associate Professor in the Department of Management of Marketing at The Hong Kong Polytechnic University. His research focuses on environmental and ethical issues relating to Chinese enterprises and consumers and his work has been published in the European Journal of Marketing, Journal of Management Studies, Journal of World Business, Journal of Business Ethics, Industrial Marketing Management, Psychology and Marketing, among others.

\section{Acknowledgment:}

This research is supported by a departmental research grant \#G-SAA9 from the Department of Management and Marketing in the Faculty of Business of The Hong Kong Polytechnic University, Hong Kong.

\footnotetext{
${ }^{1}$ Corresponding Author: Professor, School of Marketing, Curtin Business School, Curtin
} University, Bentley, WA 6102, Australia. Phone: +61 (8) 9266 3744, Fax: +61 (8) 92663937 (Email: piyush.sharma@curtin.edu.au)

${ }^{2}$ Associate Professor, Department of Management and Marketing, Faculty of Business, The Hong Kong Polytechnic University, Hung Hom, Kowloon, Hong Kong, Phone: +852-27667110, Fax: +852-2765-0611 (Email: ricky.yk.chan@polyu.edu.hk) 


\section{Demystifying deliberate counterfeit purchase behavior: Towards a unified conceptual framework}

Purpose - This paper introduces a unified conceptual framework for deliberate counterfeit purchase behavior by combining its diverse economic, ethical and socio-psychological perspectives using cognitive dissonance theory. Specific hypotheses are put forth about the interrelationships among counterfeit proneness, ethical judgments, subjective norms, counterfeit product evaluation and purchase intentions.

Design/methodology/approach - A field-survey with 380 shoppers (who had ever purchased a counterfeit product) in Hong Kong across four frequently counterfeited product categories (backpack, luxury watch, software and movie DVD) with varying levels of involvement, usage context and purchase motivation.

Findings - As hypothesized, counterfeit proneness positively influences ethical judgments and subjective norms about buying a counterfeit product, which in turn positively affect the counterfeit product evaluation and purchase intentions. All these effects are fairly stable across the four product categories, which suggests robustness of the proposed unified model.

Research limitations/implications - Using Hong Kong as the research setting and a relatively younger sample of ethnic Chinese consumers helps ensure high internal validity but it may also restrict the generalizability of the findings. Future research with a more diverse sample of consumers would help replicate the results reported in this paper. The conceptual framework may also be extended by including variables such as consumer innovativeness, risk-taking and change-seeking as antecedents of counterfeit purchase behavior and usage.

Practical implications - Findings show that consumers are influenced by a combination of individual and sociological factors when they decide whether to buy and use counterfeit products. Hence, marketers and authorities need a multi-pronged strategy to curb the growing demand and usage of counterfeit products, especially among ethnic Chinese consumers. These results may also help identify consumer segments more prone to counterfeit purchase behavior and to develop special communication to target them more effectively.

Originality/value - Past studies mostly explore the 'direct' and 'independent' effects of consumer attitudes, ethical judgments and subjective norms on their counterfeit purchase behavior, ignoring their impact on each other and the roles of 'counterfeit proneness' and 'product evaluation'. This paper addresses all these gaps with a unified conceptual framework that incorporates all these constructs using cognitive dissonance theory and provides useful insights about their direct and indirect effects on each other.

Keywords - Counterfeit proneness, ethical judgments, product evaluation, purchase intentions, subjective norms

Type of Paper - Research paper 


\section{INTRODUCTION}

Despite growing research into deliberate counterfeit purchaser behavior (e.g., Bian, Haque and Smith, 2015; Chen et al., 2015; Randhawa, Calantone and Voorhees, 2015; Stöttinger and Penz, 2015; Zhan, Sharma and Chan, 2015), there are still many mixed findings and unanswered questions. For example, some studies find a positive effect of attitude towards counterfeiting on deliberate counterfeit purchase intentions (e.g., Maldonado and Hume, 2005; Teah, Phau and Huang, 2015; Wee, Tan and Cheok, 1995) or even past purchase behavior (e.g., Penz and Stöttinger, 2005) but others find no effects on purchase intentions (e.g., Hoe, Hogg and Hart., 2003) or on past purchase behavior (e.g., de Matos, Ituassu and Rossi, 2007; Walthers and Buff, 2008).

Most studies also find a negative effect of subjective norms against counterfeiting and perceived social risk on counterfeit purchase behavior but some do not (e.g., Shaari and Halim, 2006; Veloutsou and Bian, 2008). Similarly, most studies show a negative effect of ethical judgment and moral beliefs on counterfeit purchase behavior but not the others (e.g., Francis, Burgess and Lu, 2015; Wang et al., 2005). In view of these mixed findings, it is not clear how exactly consumer attitudes, subjective norms, ethical judgments and moral beliefs influence the decision-making process underlying counterfeit purchase behavior.

One of the reasons for these mixed findings may be that prior studies mostly explore the 'independent' effects of consumer attitudes (Phau and Teah, 2009; Teah et al., 2015), ethical judgments (Maldonado and Hume, 2005), moral beliefs (Moores and Chang, 2006; Tan, 2002) and subjective norms (de Matos et al., 2007) on counterfeit purchase intentions. Hence, it is not clear how these factors may affect each other or have a combined influence on counterfeit purchase behavior. This paper uses cognitive dissonance theory to develop a 
unified conceptual framework, which includes counterfeit proneness, ethical judgments and subjective norms, and allows the study of their independent as well as combined effects.

Past studies also focus on the 'direct' effects of consumer attitudes, ethical judgments, moral beliefs and subjective norms on counterfeit purchase behavior (e.g., Ang et al., 2001; Chapa, Minor and Maldonado, 2006; de Matos et al., 2007; Kwong et al., 2003; Maldonado and Hume, 2005; Wang et al., 2005) and overlook the mediating role of 'product evaluation', a key element of consumer decision-making process as a driver of purchase intentions and behavior (Lee, Lee and Lee, 2013; Sharma, 2011a). This paper includes product evaluation as a mediator of the counterfeit purchase process to address this gap.

'Counterfeit proneness' is a general tendency to prefer and purchase counterfeit products (Sharma and Chan, 2011) and it is used to predict counterfeit purchase behavior (Klarmann, Wiedmann and Hennigs, 2013; Michaelidou and Christodoulides, 2011; Phau, Teah and Lwin, 2014). However, there is hardly any research on the underlying mechanism by which counterfeit proneness may affect the evaluation and purchase of counterfeit products and there is no consensus about the role played by consumers' ethical judgments and subjective norms in the process by which counterfeit proneness affects their evaluation and purchase intentions for counterfeit products. This paper includes counterfeit proneness as the driver of counterfeit purchase process to address these gaps.

All the hypotheses are tested using data collected in a field-survey with 380 adult ethnic Chinese local shoppers (who had ever bought counterfeit products) in Hong Kong, a market with widespread availability of counterfeit products. This study would pave the way for a better understanding of deliberate counterfeit purchase behavior by providing some fresh insights into its underlying mechanism (Chen et al., 2015; Randhawa et al., 2015; Stöttinger and Penz, 2015; Teah et al., 2015; Zhan et al., 2015) 


\section{CONCEPTUAL FRAMEWORK AND HYPOTHESES}

According to the economic view of non-deceptive counterfeiting, low-income individuals prefer counterfeits because they cannot afford the genuine brands but it does not explain why even some high-income individuals deliberately purchase counterfeits (Gentry, Putrevu and Shultz, 2006; Valette-florence, 2012; Wiedmann, Hennigs and Klarmann, 2012). The sociopsychological perspective addresses this limitation by showing that factors such as novelty (Gentry et al., 2001), peer-group influence (Penz, Schlegelmilch and Stöttinger, 2009), trial before purchase of an expensive original (Gentry et al., 2006), attitudes toward luxury brands (Wilcox, Kim and Sen, 2009) and counterfeits availability (Commuri, 2009) may also drive deliberate counterfeit purchase. Similarly, the ethical perspective offers moral beliefs (e.g., Moores and Chang, 2006) and ethical judgments (e.g., Thong and Yap, 1998; Wagner and Sanders, 2001) as alternate explanations for deliberate purchase or avoidance of counterfeit products. This paper uses cognitive dissonance as an overarching theory to combine all these diverse perspectives to develop a unified conceptual framework (Figure 1).

\section{$<$ Insert Figure 1 about here $>$}

\section{Cognitive Dissonance Theory}

According to the cognitive dissonance theory, individuals seek to maintain consistency or internal harmony among their attitudes, values and opinions; and any cognitive inconsistency serves as an important signal for errors in one's system of beliefs (Festinger, 1962). Others have clarified that cognitive consistency is not a motivational force in itself, but an accidental outcome of epistemic processes that aim at validating propositions that are desired by people and invalidating their undesirable propositions (Kruglanski and Shteynberg, 2012). Put simply, people are often more concerned with what makes them feel good and is consistent with their general attitudes than what is accurate in a given situation (Gawronski, 2012). 
Marketing researchers provide evidence of such efforts to maintain cognitive consistency in a wide range of contexts, including ethical decision-making by marketing managers (Fraedrich and Ferrell, 1992), consumer response to relationship marketing (Sheth and Parvatiyar, 1995) and experiential marketing (Schmitt, 1999), negative online reviews (Sen and Lerman, 2007) and word-of-mouth communications (De Matos and Rossi, 2008), role of leaders in internal marketing (Wieseke et al., 2009), cause-related marketing (Edmondson and Lafferty, 2014) environmental concerns (Kwon, Englis and Mann, 2015) and even counterfeit purchase behavior (Jirotmontree, 2013; Wilcox et al., 2009).

Wilcox et al. (2009) argue that consumers are guided by their desire to maximize the consistency between the products they consume and their central beliefs, attitudes, and values (Snyder and DeBono, 1985). Hence, consumer preference for a counterfeit brand and the subsequent negative change in their preference for a real brand are greater when their luxury brand attitudes serve a social-adjustive rather than value-expressive function. Similarly, moral beliefs about counterfeit consumption affect consumers' counterfeit brand preferences only when their luxury brand attitudes serve a value-expressive function. Jirotmontree (2013) also argues that counterfeit buyers form new positive attitudes towards counterfeits to rise above their unfavorable connotations and feel less burden and guilt, which in turn makes it easier it is for them carry on buying counterfeit products. This paper argues for a similar cognitive consistency among consumers' counterfeit proneness, subjective norms, ethical judgments, product evaluation and purchase intentions, to develop its unified framework.

\section{Counterfeit proneness (CFP)}

Counterfeit proneness is defined as the "general tendency of consumers to like, prefer, purchase, and use counterfeit products" and it is a relatively stable consumer trait (Sharma and Chan, 2011). By tapping into the affective and behavioral aspects of counterfeit purchase, 
in addition to the cognitive and socio-normative aspects captured by the attitude towards counterfeiting, counterfeit proneness represents an intrinsic characteristic of consumers (Sharma and Chan, 2011). In fact, there is growing evidence about a positive association between counterfeit proneness and counterfeit purchase intentions (Klarmann et al., 2013; Michaelidou and Christodoulides, 2011; Phau et al., 2014). Hence, as follows:

H1: CFP has a positive effect on the purchase intention for a counterfeit product.

According to the cognitive dissonance theory (Festinger, 1962), people tend to seek consistency among their cognitions (e.g., attitudes, beliefs and opinions) and behaviors. Any inconsistency between cognitions and behaviors leads to cognitive-dissonance, which makes people uncomfortable and they try to reduce alleviate this by altering either their cognitions or behaviors in order to make them more consistent or congruent with each other. Research on deliberate counterfeit purchase behavior also shows that consumers may experience cognitive-dissonance from their purchase of counterfeit products because it is generally perceived as an unethical behavior (Jirotmontree, 2013).

Consumers may try to reduce this dissonance by altering their attitude towards the counterfeit product with a biased evaluation process that considers the counterfeit product as good as or even better than its genuine version (de Matos et al., 2007). Consumers with high counterfeit proneness are more likely to show such a biased favorable evaluation of counterfeit products because it would also make them feel less guilty when buying a counterfeit (Sharma and Chan, 2011). In fact, consumers with positive attitudes towards counterfeit products do not even see these as inferior than their genuine versions (Nia and Zaichkowsky, 2000) and counterfeit owners also evaluate these products more favorably (Bian and Moutinho, 2011). Hence, the following hypothesis:

H2: CFP has a positive effect on the evaluation of a counterfeit product. 


\section{Subjective norms about buying a counterfeit product (SUB)}

Subjective norms are defined as the "represented expectations of relevant others" and are comprised of normative beliefs and motivation to comply with those beliefs (Fishbein and Ajzen, 1975). According to the theory of reasoned action (TRA), individual attitudes and subjective norms influence behavioral intentions, which may predict actual behavior (Fishbein and Ajzen, 1975). The theory of planned behavior (TPB) extends the theory of reasoned action by including perceived behavioral control (PBC), the perceived ability to perform a behavior (Ajzen, 1991). However, perceived behavioral control (PBC) may not play a major role in deliberate counterfeit purchase behavior because it is a completely voluntary act in which the customers knowingly and willingly purchase counterfeit products (Moores and Chang, 2006; Rutter and Bryce, 2008).

Prior research shows that individual characteristics such as counterfeit proneness may predispose consumers towards a preference for counterfeit products, to help them ensure a consistency between their personality traits, subjective norms, and usual behavioral patterns (Klarmann et al., 2013; Michaelidou and Christodoulides, 2011; Phau et al., 2014). High counterfeit prone consumers may even perceive counterfeit purchase as being endorsed by their significant others because this may help them resolve any dissonance associated with such behavior (Sharma and Chan, 2011). This line of reasoning is consistent with the idea that non-deceptive counterfeit purchase is a deliberate (volitional) behavior (Stöttinger and Penz, 2015) and that counterfeit buyers may actually consider it as a normatively correct behavior due to favorable subjective norms of their peers (Albers-Miller, 1999), friends and family members (Prendergast, Chuen and Phau, 2002), significant others (Penz and Stöttinger, 2005) or even society at large (Jirotmontree, 2013). Hence, the following hypothesis: 
H3: Counterfeit proneness has a positive effect on the subjective norms about buying a counterfeit product.

Prior research shows positive effects of perceived social consensus (Tan, 2002) and favorable opinion of significant others (Albers-Miller, 1999; Penz and Stöttinger, 2005, 2008; Prendergast et al., 2002) on counterfeit purchase. Rampant counterfeit consumption in some countries also suggests social acceptance of such behavior, which makes people in those countries view the availability, purchase and use of counterfeits it as a common practice with little or no unfavorable connotations (Jirotmontree, 2013). According to cognitive dissonance theory, presence of such favorable subjective norms may help the consumers overcome any negative perceptions about the quality of counterfeit products and probably even create a favorable bias in their evaluations of counterfeit products because it would help them achieve cognitive consistency and avoid any cognitive dissonance. Hence, the following hypothesis:

H4: Subjective norms about buying a counterfeit product have a positive effect on the evaluation of that counterfeit product.

Subjective norms influence consumer attitudes and purchase of controversial products (Xu, Summers and Belleau, 2004) and choice of tourism destination (Quintal, Lee and Soutar, 2010), because consumers believe that their significant others also have favorable subjective norms about such behaviors. Similar results are reported in counterfeit research showing that subjective norms of peers (Albers-Miller, 1999), friends and family members (Prendergast et al., 2002), significant others (Penz and Stöttinger, 2005) and the society (Jirotmontree, 2013; Tan, 2002) has a positive effect on consumers' counterfeit purchase intentions. Based on this, the following hypothesis is put forth:

H5: Subjective norms about buying a counterfeit product have a positive effect on the purchase intentions for that counterfeit product. 


\section{Ethical judgments about buying a counterfeit product (ETH)}

Ethical judgments are defined as an evaluation of an ethical issue based on an individual's ethical or moral beliefs (Hunt and Vitell, 1986). Prior research on the ethical perspective of counterfeiting uses Hunt and Vitell's (1986) theory of ethical decision-making (e.g., Thong and Yap, 1998; Wagner and Sanders, 2001) to show that consumers form an ethical judgment about an ethical issue based on an evaluation of possible alternatives or actions to resolve the ethical dilemma, which in turn influences their moral intention and moral behavior, subject to situational constraints (Hunt and Vitell, 1986). Past studies on counterfeit purchase highlight the importance of moral beliefs and ethical judgments on consumer attitudes (Chaudhry and Stumpf, 2011; Maldonado and Hume, 2005), motivations (Penz and Stöttinger, 2012; Wiedmann et al., 2012) as well as purchase intentions and behaviors (Wilcox et al., 2009).

According to cognitive dissonance theory, counterfeit prone consumers who experience a dissonance between their attitudes, beliefs and behaviors towards counterfeit products, would alter their moral beliefs and ethical judgments by making them more favorable and consistent with their positive attitudes and preference towards counterfeits. In fact, prior research shows that some high counterfeit prone buyers actually consider purchase of counterfeits to be worthwhile and helpful in enhancing societal welfare (Ang et al., 2001) or even legitimate and ethical (Chaudhry and Stumpf, 2011), in a phenomenon known as 'moral profiteering' (Poddar et al., 2012). In other words, high counterfeit prone consumers would have more favorable ethical judgments about purchase of counterfeits. Hence,

H6: Counterfeit proneness has a positive effect on the ethical judgments about buying a counterfeit product.

Prior research on ethical consumption shows that the ethical beliefs and values of the consumers clearly drive their ethical behavior, and in this process product attributes may aid 
a desired outcome or value (Shaw and Clarke, 1999). In other words, ethical consumer may overemphasize some product attributes over the others in order to justify their purchase of ethical products to maintain cognitive consistency and avoid any dissonance. A similar argument may be made in the context of counterfeit products, wherein consumers with favorable ethical judgments about buying counterfeit products may also perceive and evaluate counterfeit products more favorably because this would help them avoid any cognitive dissonance due to a possible mismatch between their beliefs and actions. Hence,

H7: Ethical judgments about buying a counterfeit product have a positive effect on the evaluation of that counterfeit product.

Many studies show a significant influence of consumer ethics, integrity or moral intentions on counterfeit purchase behavior across various product categories e.g., music CDs and DVDs (Ang et al., 2001; Wang, 2005), personal accessories (Maldonado and Hume, 2005), software (Moores and Chang, 2006) and others (de Matos et al., 2007). Consumers with favorable moral beliefs about counterfeit purchase behavior are more likely to buy counterfeit brands than those with unfavorable moral beliefs (Wilcox et al., 2009). Hence, consumers who consider it ethically acceptable to buy counterfeit products would be more likely to buy them, as hypothesized below:

H8: Ethical judgments about buying a counterfeit product have a positive effect on the purchase intentions for that counterfeit product.

\section{Counterfeit product evaluation (CPE) and purchase intentions (CPI)}

Product evaluation is an overall assessment of its various economical, functional and other attributes, including price, quality, reliability and image; and it is an important predictor of purchase intentions (Dodds, Monroe and Grewal, 1991). In the counterfeit purchase 
context, even if customers have very positive ethical judgments or subjective norms towards buying a counterfeit product, they may not want to buy that counterfeit product due to other reasons such as product quality, price difference vis-à-vis its genuine version etc. Hence, the evaluation of a counterfeit product may have a direct positive effect on their purchase intentions for that counterfeit product, as hypothesized below:

H9: Evaluation of a counterfeit product has a positive effect on the purchase intentions for that counterfeit product.

\section{METHODOLOGY}

\section{Sample and Data Collection}

This study used a field-survey in Hong Kong with a team of 10 well-trained student helpers who did not know the research objectives and hypotheses (to minimize the demand effects). Hong Kong is an appropriate setting for this study as counterfeit goods are widely available locally as well as in nearby Chinese cities, and many consumers buy these products regularly (Cheung and Prendergast, 2006a, b; Harvey and Walls, 2003; Sharma and Chan, 2011). Hong Kong is also an important entry point for China, the biggest producer and consumer of counterfeit products in the world (Jiang, 2014; Li and Seaton, 2015).

The student helpers intercepted about 2000 local Chinese shoppers in four major shopping areas in Hong Kong (e.g., Mong Kok, Tsim Sha Tsui, Causeway Bay, and Shatin) and collected 610 completed questionnaires. Out of these 380 participants indicated that they had ever purchased a counterfeit product, hence this is the final sample size for this study, giving an effective response rate of about $19 \%$, which seems reasonably high for surveys using similar mall-intercept approach (Bush and Hair Jr., 1985). Each participant received a HK\$ 20 coupon (about USD 2.50) for use at any branch of a local Fast-food chain, as a token 
of appreciation for their help. No personally identifiable information such as names or contact details was collected from the participants in order to ensure complete anonymity and the participants completed the questionnaires on their own and handed them back to the surveyors in sealed unmarked envelopes to ensure confidentiality of their responses.

\section{Measures}

Existing scales were used to operationalize all the other constructs in this study including the six-item counterfeit proneness (Sharma and Chan, 2011), subjective norms (Ajzen, 1991), ethical judgment about buying a counterfeit product (Kwong et al., 2009), and product evaluation and purchase intention (de Matos et al., 2007). All the scales use a seven-point Likert-type response format (ranging from $1=$ strongly disagree to $7=$ strongly agree), except for purchase intentions $(1=$ very unlikely to $7=$ very likely $)$. The participants also reported frequency of counterfeit purchase in last three months (FRQ) besides demographics (age, gender, education, and occupation). All these are used as control variables.

\section{Product Categories}

A pre-test with 60 adult consumers (with a similar profile as the participants in the main study) helped shortlist the product categories for this study. They were asked to rate 30 product categories on three characteristics (i.e., involvement level, usage context, and purchase motivation) as well as their familiarity and relevance, which helps classify product categories in a systematic manner based on past research (e.g., Sharma, 2011b). The following four product categories were chosen as they best represent the three characteristics and score high on product familiarity and relevance: 1) Luxury watch (high involvement, public usage, hedonic motivation); 2) Anti-virus software (high involvement, private usage, utilitarian motivation); 3) Movie DVD (low involvement, private usage, hedonic motivation); and 4) Backpack (low involvement, public usage, utilitarian motivation). 


\section{Procedure}

The study used a between-subjects design, wherein each participant answered questions related to only one product category, to minimize the possibility of respondent fatigue, boredom, and carry-over effects. The respondents were randomly assigned to one of the four product categories and no significant differences were found in their past usage, relevance or familiarity across the four product categories. As shown in Table 1, the sample has a similar proportion of males (51\%) and females (49\%); most participants are under 40 years old (90\%), have education above high-school (66\%), are white collar employees and students $(78 \%)$ and $38 \%$ of them having bought a counterfeit product in the last three months.

$<$ Insert Table 1 about here $>$

\section{DATA ANALYSIS AND RESULTS}

Confirmatory factor analysis (CFA) on all the scales with AMOS 6.0 (Anderson and Gerbing, 1988; Byrne, 2004) shows a close fit $\left(\chi^{2}=241.30, \mathrm{p}<.001 ; \mathrm{df}=145, \chi^{2} / \mathrm{df}=1.66 ; \mathrm{GFI}=.95\right.$, $\mathrm{NFI}=.96, \mathrm{CFI}=.98, \mathrm{RMSEA}=.042$, and SRMR $=.054)$. All the fit parameters are better than the cut-off values $(\mathrm{NFI}>.90, \mathrm{CFI}>.95, \mathrm{RMSEA}<.06$, SRMR $<.08)$ advised by $\mathrm{Hu}$ and Bentler $(1999)$ and $\left(1<\chi^{2} / d f<3\right)$ by Wheaton et al. (1977). Table 2 shows the psychometric properties of all the scale items, including standardized factor loadings, squared multiple correlations, and descriptives (mean and standard deviation).

$<$ Insert Table 2 about here $>$

All parameter estimates $(\lambda)$ are large and have significantly big t-values (11.30-19.98) (Anderson and Gerbing, 1988) with the values of all squared multiple correlations (.53 -.78) and average variance extracted $(.59-.71)$ higher than .50 , showing high convergent validity (Fornell and Larcker, 1981). Average variance extracted for each factor also exceeds squared 
correlations with all the other constructs, showing discriminant validity (Fornell and Larcker, 1981). Table 3 shows the correlation coefficients among all the variables.

$<$ Insert Table 3 about here $>$

Next, the structural model (Model 1) using the pooled data from all the four product categories shows a close fit $\left(\chi^{2}=222.11, \mathrm{p}<.001, \mathrm{df}=144, \chi^{2} / \mathrm{df}=1.54 ; \mathrm{GFI}=.95, \mathrm{NFI}\right.$ $=.96, \mathrm{CFI}=.98, \mathrm{RMSEA}=.032, \mathrm{SRMR}=.038)$ with all the path coefficients significant and in the expected directions. Specifically, CFP has a significant positive influence on CPI (H1: $\beta=.21, p<.01)$, CPE $(H 2: \beta=.25, p<.01)$ and SUB $(H 3: \beta=.54, p<.001)$, and SUB has a significant positive effect on both CPE $(\mathrm{H} 4: \beta=.40, \mathrm{p}<.001)$ and CPI $(\mathrm{H} 5: \beta=.38, \mathrm{p}<.001)$. CFP also has a significant positive effect on ETH $(\mathrm{H} 6: \beta=.29, \mathrm{p}<.001)$, and ETH has a significant positive effect on both CPE $(\mathrm{H} 7: \beta=.29, \mathrm{p}<.001)$ and CPI $(\mathrm{H} 8: \beta=.14, \mathrm{p}<.05)$. Finally, CPE has a significant positive influence on CPI (H9: $\beta=.43, p<.001)$. Thus, all the nine hypotheses are supported. Table 4 shows all these results.

$<$ Insert Table 4 about here $>$

As this study includes four different product categories, an additional multi-group model (Model 2) was tested to see if all the hypothesized relationships are valid for each product category. Model 2 also shows a close fit $\left(\chi^{2}=872.99, \mathrm{p}<.001, \mathrm{df}=548, \chi^{2} / \mathrm{df}=1.59\right.$; $\mathrm{GFI}=.90, \mathrm{NFI}=.91, \mathrm{CFI}=.95, \mathrm{RMSEA}=.040, \mathrm{SRMR}=.057)$ with all the path coefficients except one (H8: ETH $\rightarrow$ CPI for Watch, $\beta=.05, p>.10)$ significant and in the expected directions. Hence, the findings seem fairly stable across the four product categories. In line with prior research (e.g., Ang et al., 2001; Wee et al., 1995), significantly higher scores for CFP, SUB, ETH, CPE and CPI are found for younger, male, less educated and students. However, none of the control variables (including FRQ) show any significant interaction with the hypothesized relationships, hence these are not discussed any further in this paper. 


\section{DISCUSSION AND CONTRIBUTION}

This paper combines the economic, ethical and socio-psychological perspectives of nondeceptive deliberate counterfeit purchase behavior using cognitive dissonance theory to develop a unified framework that incorporates the direct effects of counterfeit proneness on subjective norms and ethical judgments and their combined effects on the evaluation and purchase intentions for counterfeits across four product categories. A field-survey with shoppers in Hong Kong (who have purchased counterfeit products in the past), shows direct effects of counterfeit proneness as well as its indirect effects through subjective norms and ethical judgments on counterfeit product evaluation and purchase intentions.

Prior research on counterfeit purchase behavior reports many mixed findings, possibly because most of them only studied the direct and independent effects of attitudes, moral beliefs and social norms on counterfeit purchase intentions, (e.g., Ang et al., 2001; Chapa et al., 2006; de Matos et al., 2007; Kwong et al., 2003; Maldonado and Hume, 2005; Wang et al., 2005) which may have prevented these studies from providing a complete picture of the motivational process that drives or inhibits counterfeit purchase behavior. This paper uses four carefully chosen product categories and a field-survey with actual shoppers in their natural setting to show that it is not just counterfeit proneness, subjective norms or ethical judgments alone, but a combination of all these factors that influences consumers' evaluation and purchase intentions for counterfeit products. This is an important contribution as it highlights the importance of taking a holistic view of counterfeit purchase and usage behavior to understand its complex underlying motivations.

Most prior studies also ignore the role of 'counterfeit product evaluation' despite considerable evidence about its influence on consumers' purchase decisions. This paper uses cognitive dissonance theory to argue that high counterfeit prone consumers are likely to try 
and avoid or overcome cognitive dissonance by aligning their various beliefs and judgments as well as evaluation of counterfeit products in line with their past purchase of counterfeit products in order to ensure cognitive consistency. The findings from the empirical study support this line of reasoning and shows that the biased (more favorable) evaluation of counterfeit product is a critical link in the influence of counterfeit proneness, subjective norms and ethical judgments on counterfeit purchase intentions.

This paper shows that counterfeit proneness influences subjective norms towards buying counterfeit products $(\beta=.54)$ to a greater extent compared to ethical judgments $(\beta$ $=.29)$. Subjective norms $(\beta=.40 \& .38)$ also have a stronger impact than ethical judgments $(\beta=.29 \& .14)$ on counterfeit product evaluation and purchase intentions respectively. From these findings it appears that the ethnic Chinese participants in this study are influenced by their subjective norms to a greater extent compared to their own ethical judgments. This is a very important finding because it helps us understand why the Chinese consumers may be more counterfeit prone compared to others and to develop suitable strategies to change the perceptions and behaviour of these consumers.

Prior research shows that past experience and satisfaction with counterfeit products generally have a positive impact on the consumers' preference and purchase intentions for them in future (Penz and Stöttinger, 2008; Tan, 2002; Tom et al., 1998; Walthers and Buff, 2008) although some show no significant effect or mixed results (de Matos et al., 2007; Yoo and Lee, 2012). This paper explains these mixed findings by showing that the counterfeit users are not only more counterfeit prone but they also have more favorable subjective norms and ethical judgments about buying counterfeit products. They also evaluate counterfeit products more favorably and have stronger purchase intentions for them. This paper uses cognitive dissonance theory to explain these findings by arguing that past purchase of 
counterfeit products may trigger a cognitive dissonance because of the inconsistency between their attitudes and behavior towards counterfeit products. In order to reduce this dissonance, these consumers may alter their subjective norms and ethical judgments about buying counterfeit products by making them more favorable and in line with their behavior.

Finally, many early studies explored counterfeit purchase behavior in only one or more product categories, which may have restricted the generalizability of their findings and also led to some non-significant or inconclusive results. In this study, four product categories were carefully chosen based on their three characteristics, namely involvement level, usage context and purchase motivation. Using multi-group SEM, the relationships among all the five constructs (counterfeit proneness, subjective norms, ethical judgments, product evaluation and purchase intentions) were shown to be fairly stable across the four product categories; which supports the robustness of the proposed unified conceptual framework.

\section{MANAGERIAL IMPLICATIONS}

This research also has many important managerial implications. First, it shows that growing counterfeit proneness may be the primary driver for counterfeit usage because of its direct effect on consumers' subjective norms and ethical judgments about buying counterfeit products as well as direct effects on counterfeit product evaluation and purchase intentions. As counterfeit proneness is a relatively stable consumer trait that develops over time with repeated exposure to and usage of counterfeit products (Sharma and Chan, 2011); marketers of genuine brands may not be able to do much about it directly. However, they may dampen its impact on the counterfeit purchase by highlighting the negative social and ethical norms associated with counterfeit usage in their communication campaigns. Governments and local authorities may also use consumer education campaigns to minimize the spread of counterfeit proneness among their citizens, especially among younger less-educated consumers. 
Interestingly, for the ethnic Chinese consumers in this study, subjective norms seem to have stronger effects on counterfeit product evaluation and purchase intentions compared to ethical judgments associated with counterfeit usage, as reflected in other studies (Bian and Forsythe, 2012). Hence, marketers of genuine brands to ethnic Chinese consumers may need to highlight the socio-normative aspects of counterfeit purchase in their communication to a greater extent compared to its ethical dimension used in their communication for the Western consumers. Specifically, for their Chinese consumers, marketers of genuine brands may use advertisements showing the 'loss of face' and 'embarrassment' in social settings if consumers are being found using counterfeit products rather than feeling 'guilty' due to its negative moral or ethical associations, which may have worked better with their Western consumers.

This research also highlights the central role played by product evaluations in the counterfeit purchase behavior by mediating the influence of counterfeit proneness, subjective norms and ethical judgments on purchase intentions (Bian and Moutinho, 2011). Hence, marketers of genuine brands would need to further highlight the superior features and benefits of their products to reduce the demand for their counterfeit versions. This would help overcome the combined impact of growing counterfeit proneness, favorable subjective norms and ineffective ethical judgments on counterfeit product evaluation and purchase intentions, especially among ethnic Chinese consumers.

To conclude, there is a need for a multi-pronged strategy to counter the growing proliferation and demand for counterfeit products by acknowledging the rising levels of counterfeit proneness (especially among ethnic Chinese consumers) and its positive impact on their subjective norms and ethical judgments about buying counterfeits. Marketers would be well-advised to understand each relationship in the proposed unified conceptual model to be able to develop suitable strategies to tackle each of these in an effective manner. 


\section{LIMITATIONS AND FUTURE RESEARCH}

This paper has a few limitations that may be addressed in future research in order to test and improve the generalizability of its findings. This study was conducted in Hong Kong, which has widespread availability and frequent usage of counterfeit goods; hence it would be useful to conduct similar research in other parts of the world to validate the unified conceptual framework proposed in this paper. Restricting the sample to ethnic Chinese consumers in this study helped ensure high internal validity by controlling the influence of cultural factors but it would be useful to explore the influence of cultural factors (e.g., individualism and uncertainty avoidance etc.) on counterfeit purchase behavior

The sample used in this study is relatively young, with $96 \%$ participants aged 50 years or below, hence the findings may not be generalizable to the general population in Hong Kong that has only $70 \%$ people in this age group (HKCSD, 2015). Finally, this paper included counterfeit proneness as the only individual psychographic antecedent of the subjective norms and ethical judgments about buying a counterfeit product. Future research may include other variables such as consumer innovativeness, risk-taking and change-seeking, to explore their influence on counterfeit purchase behavior and usage.

\section{REFERENCES}

Ajzen, I. (1991), "The Theory of Planned Behavior: Some Unresolved Issues", Organization Behavior and Human Decision Processes, Vol. 50 No. 2, pp. 179-211.

Albers-Miller, N.D. (1999), "Consumer misbehavior: Why people buy illicit goods?", Journal of Consumer Marketing, Vol. 16 No. 3, pp. 273-287.

Anderson, J.C. and Gerbing, D.W. (1988), "Structural equation modeling in practice: A review and recommended two step approach", Psychological Bulletin, Vol. 103 No. 3, pp. 411-423.

Ang, S.H., Cheng, P.S., Lim, E.A.C. and Tambyah, S.K. (2001), "Spot the difference: consumer responses towards counterfeits", Journal of Consumer Marketing, Vol. 18 No. 3, pp. 219-235. 
Bian, Q. and Forsythe, S. (2012), "Purchase intention for luxury brands: A cross cultural comparison", Journal of Business Research, Vol. 65 No. 10, pp. 1443-1451.

Bian, X., Haque, S. and Smith, A. (2015), "Social power, product conspicuousness, and the demand for luxury brand counterfeit products", British Journal of Social Psychology, Vol. 54 No. 1, pp. 37-54.

Bian, X. and Moutinho, L. (2011), "Counterfeits and branded products: effects of counterfeit ownership", Journal of Product \& Brand Management, Vol. 20 No. 5, pp. 379-393.

Bush, A.J. and Hair Jr., J.F. (1985), "An assessment of the mall intercept as a data collection method", Journal of Marketing Research, Vol. 22 No. 2, pp. 158-167.

Byrne, B.M. (2004), "Testing for Multigroup Invariance Using AMOS Graphics: A Road Less Traveled", Structural Equation Modeling, Vol. 11 No. 2, pp. 272-300.

Chapa, S., Minor, M.S. and Maldonado, C. (2006), "Product Category and Origin Effects on Consumer Responses to Counterfeits: Comparing Mexico and the U.S.", Journal of International Consumer Marketing, Vol. 18 No. 4, pp. 79-99.

Chaudhry, P.E. and Stumpf, S.A. (2011), "Consumer complicity with counterfeit products", Journal of Consumer Marketing, Vol. 28 No. 2, pp. 139-151.

Chen, J., Teng, L., Liu, S. and Zhu, H. (2015), "Anticipating regret and consumers' preferences for counterfeit luxury products", Journal of Business Research, Vol. 68 No. 3, pp. 507-515.

Cheung, W.-L. and Prendergast, G. (2006a), "Buyers' perceptions of pirated products in China", Marketing Intelligence \& Planning, Vol. 24 No. 5, pp. 446-462.

Cheung, W.-L. and Prendergast, G. (2006b), "Exploring the Materialism and Conformity Motivations of Chinese Pirated Product Buyers", Journal of International Consumer Marketing, Vol. 18 No. 3, pp. 7-31.

Commuri, S. (2009), "The Impact of Counterfeiting on Genuine-Item Consumers' Brand Relationships", Journal of Marketing, Vol. 73 No. 3, pp. 86-98.

de Matos, C.A., Ituassu, C.T. and Rossi, C.A.V. (2007), "Consumer attitudes toward counterfeits: a review and extension", Journal of Consumer Marketing, Vol. 24 No. 1, pp. 36-47.

De Matos, C.A. and Rossi, C.A.V. (2008), "Word-of-mouth communications in marketing: a meta-analytic review of the antecedents and moderators", Journal of the Academy of Marketing Science, Vol. 36 No. 4, pp. 578-596.

Dodds, W.B., Monroe, K.B. and Grewal, D. (1991), "The Effects of Price, Brand, and Store Information on Buyers' Product Evaluations", Journal of Marketing Research, Vol. 28 No. 3, pp. 307-319.

Edmondson, D.R. and Lafferty, B.A. (2014), "A model of relevant antecedents and outcome variables for cause-related marketing", Journal of Management and Marketing Research, Vol. 14 No., pp. 1-13. 
Festinger, L. (1962), A theory of cognitive dissonance, 2 ed., Stanford University Press, Stanford, CA.

Fishbein, M. and Ajzen, I. (1975), Belief, Attitude, Intention, and Behavior: An Introduction to Theory and Research, ed., Addison-Wesley, Reading, MA.

Fornell, C. and Larcker, D.F. (1981), "Evaluating Structural Equation Models with Unobservable Variables and Measurement Error", Journal of Marketing Research, Vol. 18 No. 1, pp. 39-50.

Fraedrich, J. and Ferrell, O.C. (1992), "Cognitive consistency of marketing managers in ethical situations", Journal of the Academy of Marketing Science, Vol. 20 No. 3, pp. 245-252.

Francis, J.E., Burgess, L. and Lu, M. (2015), "Hip to be cool: A Gen Y view of counterfeit luxury products", Journal of Brand Management [Online].

Gawronski, B. (2012), "Back to the future of dissonance theory: Cognitive consistency as a core motive", Social Cognition, Vol. 30 No. 6, pp. 652-668.

Gentry, J.W., Putrevu, S. and Shultz, C.J. (2006), "The Effects of Counterfeiting on Consumer Search", Journal of Consumer Behaviour, Vol. 5 No. May-June, pp. 245256.

Gentry, J.W., Putrevu, S., Shultz, C.J. and Commuri, S. (2001), "How Now Ralph Lauren? The Separation of Brand and Product in a Counterfeit Culture". In: Gilly, M.C. and Meyers-Levy, J., eds. Advances in Consumer Research. pp. 258-265.

Harvey, P.J. and Walls, W.D. (2003), "Laboratory markets in counterfeit goods: Hong Kong versus Las Vegas", Applied Economics Letters, Vol. 10 No. 14, pp. 883-887.

HKCSD (2015), Hong Kong Population Statistics [Online]. Hong Kong: Census and Statistics Department, The Government of Hong Kong SAR. Available: http://www.censtatd.gov.hk/hkstat/sub/sp150.jsp?tableID $=002 \& I D=0 \&$ productType $=$ $\underline{8}$ [Accessed 21 May 2015.

Hoe, L., Hogg, G. and Hart., S. (2003), "Fakin' It: Counterfeiting and Consumer Contradictions". In: Turley, D. and Brown, S., eds. European Advances in Consumer Research, Provo, UT. pp. 60-67.

Hu, L.-t. and Bentler, P.M. (1999), "Cutoff criteria for fit indexes in covariance structure analysis: conventional criteria versus new alternatives", Structural Equation Modeling, Vol. 6 No. 1, pp. 1-55.

Hunt, S.D. and Vitell, S. (1986), "A General Theory of Marketing Ethics", Journal of Macromarketing, Vol. 6 No. 1, pp. 5-16.

Jiang, L. (2014), "Call for Copy-The culture of counterfeit in China", Journal of Chinese Economics, Vol. 2 No. 2. 
Jirotmontree, A. (2013), "Business Ethics and Counterfeit Purchase Intention: A Comparative Study on Thais and Singaporeans", Journal of International Consumer Marketing, Vol. 25 No. 4, pp. 281-288.

Klarmann, C., Wiedmann, K.-P. and Hennigs, N. (2013), Luxury Longing and Counterfeit Complicity: A Consumer Typology based on the Perception of Luxury Value and Counterfeit Risk. In: Wiedmann, K.-P. and Hennigs, N. (eds.) Luxury Marketing: A Challenge for Theory and Practice. Springer, pp. 261-277.

Kruglanski, A.W. and Shteynberg, G. (2012), Cognitive consistency as means to an end: How subjective logic affords knowledge. In: Gawronski, B. and Strack, F. (eds.) Cognitive consistency: A fundamental principle in social cognition. New York, NY: Guildford, pp. 245-264.

Kwon, W.-S., Englis, B. and Mann, M. (2015), "Are third-party green-brown ratings believed?: The role of prior brand loyalty and environmental concern", Journal of Business Research [Online].

Kwong, K.K., Yau, O.H.M., Lee, J.S.Y., Sin, L.Y.M. and Tse, A.C.B. (2003), "The Effects of Attitudinal and Demographic Factors on Intention to Buy Pirated CDs: The Case of Chinese Consumers", Journal of Business Ethics, Vol. 47 No. 3, pp. 223-235.

Kwong, K.K., Yu, W.Y.P., Leung, J.W.K. and Wang, K. (2009), "Attitude Toward Counterfeits and Ethnic Groups: Comparing Chinese and Western Consumers Purchasing Counterfeits", Journal of Euromarketing, Vol. 18 No. 3, pp. 157-168.

Lee, J.K., Lee, B.-K. and Lee, W.-N. (2013), "Country-of-origin fit's effect on consumer product evaluation in cross-border strategic brand alliance", Journal of Business Research, Vol. 66 No. 3, pp. 354-363.

Li, T. and Seaton, B. (2015), "Emerging Consumer Orientation, Ethical Perceptions, and Purchase Intention in the Counterfeit Smartphone Market in China", Journal of International Consumer Marketing, Vol. 27 No. 1, pp. 27-53.

Maldonado, C. and Hume, E.C. (2005), "Attitudes Toward Counterfeit Products: An Ethical Perspective", Journal of Legal, Ethical and Regulatory Issues, Vol. 8 No. 2, pp. 105 117.

Michaelidou, N. and Christodoulides, G. (2011), "Antecedents of attitude and intention towards counterfeit symbolic and experiential products", Journal of Marketing Management, Vol. 27 No. 9-10, pp. 976-991.

Moores, T.T. and Chang, J.C. (2006), "Ethical Decision Making in Software Piracy: Initial Development and Test of a Four-Component Model", MIS Quarterly, Vol. 30 No. 1, pp. 167-180.

Nia, A. and Zaichkowsky, J.L. (2000), "Do Counterfeits Devalue the Ownership of Luxury Brands?", Journal of Product \& Brand Management, Vol. 9 No. 7, pp. 485-497.

Penz, E., Schlegelmilch, B.B. and Stöttinger, B. (2009), "Voluntary Purchase of Counterfeit Products: Empirical Evidence From Four Countries", Journal of International Consumer Marketing, Vol. 21 No. 1, pp. 67-84. 
Penz, E. and Stöttinger, B. (2005), "Forget the "Real" Thing - Take the Copy! An Explanatory Model for the Volitional Purchase of Counterfeit Products". In: Menon, G. and Rao, A.R., eds. Advances in Consumer Research, Duluth, MN. pp. 568-575.

Penz, E. and Stöttinger, B. (2008), "Original brands and counterfeit brands - do they have anything in common?", Journal of Consumer Behaviour, Vol. 7 No. 2, pp. 146-163.

Penz, E. and Stöttinger, B. (2012), "A comparison of the emotional and motivational aspects in the purchase of luxury products versus counterfeits", Journal of Brand Management, Vol. 19 No. 7, pp. 581-594.

Phau, I. and Teah, M. (2009), "Devil wears (counterfeit) Prada: a study of antecedents and outcomes of attitudes towards counterfeits of luxury brands", Journal of Consumer Marketing, Vol. 26 No. 1, pp. 15-27.

Phau, I., Teah, M. and Lwin, M. (2014), "Pirating pirates of the Caribbean: The curse of cyberspace", Journal of Marketing Management, Vol. 30 No. 3-4, pp. 312-333.

Poddar, A., Foreman, J., Banerjee, S.S. and Ellen, P.S. (2012), "Exploring the Robin Hood effect: Moral profiteering motives for purchasing counterfeit products", Journal of Business Research, Vol. 65 No. 10, pp. 1500-1506.

Prendergast, G., Chuen, L.H. and Phau, I. (2002), "Understanding consumer demand for nondeceptive pirated brands", Marketing Intelligence \& Planning, Vol. 20 No. 7, pp. 405416.

Quintal, V.A., Lee, J.A. and Soutar, G.N. (2010), "Risk, uncertainty and the theory of planned behavior: A tourism example", Tourism Management, Vol. 31 No. 6, pp. 797-805.

Randhawa, P., Calantone, R.J. and Voorhees, C.M. (2015), "The pursuit of counterfeited luxury: An examination of the negative side effects of close consumer-brand connections", Journal of Business Research, Vol. 68 No. 11, pp. 2395-2403.

Rutter, J. and Bryce, J. (2008), "The Consumption of Counterfeit Goods: 'Here Be Pirates?'", Sociology, Vol. 42 No. 6, pp. 1146-1164.

Schmitt, B. (1999), "Experiential marketing", Journal of Marketing Management, Vol. 15 No. 1-3, pp. 53-67.

Sen, S. and Lerman, D. (2007), "Why are you telling me this? An examination into negative consumer reviews on the web", Journal of Interactive Marketing, Vol. 21 No. 4, pp. 76-94.

Shaari, H. and Halim, F. (2006), "Consumer Purchase of Pirated VCD: Do Non-Price Factors Matter?", International Journal of Business and Society, Vol. 7 No. 2, pp. 119-131.

Sharma, P. (2011a), "Country-of-Origin Effects in Developed vs. Emerging Markets: Exploring the Contrasting Roles of Materialism and Value-Consciousness", Journal of International Business Studies, Vol. 42 No. 2, pp. 285-306. 
Sharma, P. (2011b), "Demystifying Cultural Differences in Country-of-Origin Effects: Exploring the Moderating Roles of Product Type, Consumption Context, and Involvement", Journal of International Consumer Marketing, Vol. 23 No. 5, pp. 344364.

Sharma, P. and Chan, R.Y.K. (2011), "Counterfeit Proneness: Conceptualization and Scale Development", Journal of Marketing Management, Vol. 27 No. 5\&6, pp. 602-626.

Shaw, D. and Clarke, I. (1999), "Belief formation in ethical consumer groups: an exploratory study", Marketing intelligence \& planning, Vol. 17 No. 2, pp. 109-120.

Sheth, J.N. and Parvatiyar, A. (1995), "Relationship marketing in consumer markets: antecedents and consequences", Journal of the Academy of Marketing Science, Vol. 23 No. 4, pp. 255-271.

Snyder, M. and DeBono, K.G. (1985), "Appeals to image and claims about quality: Understanding the psychology of advertising", Journal of Personality and Social Psychology, Vol. 49 No. 3, pp. 586-597.

Stöttinger, B. and Penz, E. (2015), "Concurrent Ownership of Brands and Counterfeits: Conceptualization and Temporal Transformation from a Consumer Perspective", Psychology \& Marketing, Vol. 32 No. 4, pp. 373-391.

Tan, B. (2002), "Understanding Consumer Ethical Decision Making With Respect to Purchase of Pirated Software", Journal of Consumer Marketing, Vol. 19 No. 2, pp. 96-111.

Teah, M., Phau, I. and Huang, Y.-a. (2015), "Devil continues to wear "counterfeit" Prada: a tale of two cities", Journal of Consumer Marketing, Vol. 32 No. 3, pp. 176-189.

Thong, J.Y.L. and Yap, C.-S. (1998), "Testing an Ethical-Decision Making Theory: The Case of Softlifting", Journal of Management Information Systems, Vol. 15 No. 1, pp. 213237.

Tom, G., Garibaldi, B., Zeng, Y. and Pilcher, J. (1998), "Consumer Demand for Counterfeit Goods", Psychology \& Marketing, Vol. 15 No. 5, pp. 405-421.

Valette-florence, P. (2012), "Luxury and counterfeiting: Issues, challenges and prospects", Journal of Brand Management, Vol. 19 No. 7, pp. 541-543.

Veloutsou, C. and Bian, X. (2008), "A cross-national examination of consumer perceived risk in the context of non-deceptive counterfeit brands", Journal of Consumer Behaviour, Vol. 7 No. 1, pp. 3-20.

Wagner, S.C. and Sanders, L.G. (2001), "Considerations in Ethical Decision Making and Software Piracy", Journal of Business Ethics, Vol. 29 No. 1/2, pp. 161-167.

Walthers, A. and Buff, C.L. (2008), "Attitudes Towards Counterfeiting and Counterfeit Products: Have they changed?", Journal of International Business \& Economics, Vol. 8 No. 3, pp. 79-87. 
Wang, C.-C. (2005), "Factors that Influence the Piracy of DVD/VCD Motion Pictures", Journal of American Academy of Business, Vol. 6 No. 2, pp. 231-237.

Wang, F., Zhang, H., Zang, H. and Ouyang, M. (2005), "Purchasing pirated software: an initial examination of Chinese consumers", Journal of Consumer Marketing, Vol. 22 No. 6, pp. 340-351.

Wee, C.-H., Tan, S.-J. and Cheok, K.-H. (1995), "Non-price Determinants of Intention to Purchase Counterfeit Goods: An Exploratory Study", International Marketing Review, Vol. 12 No. 6, pp. 19-46.

Wheaton, B., Muthen, B., Alwin, D.F. and Summers, G.F. (1977), Assessing reliability and stability in panel models. In: Heise, D.R. (ed.) Sociological methodology. San Francisco: Jossey-Bass, pp. 84-136.

Wiedmann, K.-p., Hennigs, N. and Klarmann, C. (2012), "Luxury consumption in the tradeoff between genuine and counterfeit goods: What are the consumers' underlying motives and value-based drivers?", Journal of Brand Management, Vol. 19 No. 7, pp. 544-566.

Wieseke, J., Ahearne, M., Lam, S.K. and Dick, R.v. (2009), "The role of leaders in internal marketing", Journal of Marketing, Vol. 73 No. 2, pp. 123-145.

Wilcox, K., Kim, H.M. and Sen, S. (2009), "Why Do Consumers Buy Counterfeit Luxury Brands?", Journal of Marketing Research, Vol. 46 No. 2, pp. 247-259.

Xu, Y., Summers, T.A. and Belleau, B.D. (2004), "Who buys American alligator?: Predicting purchase intention of a controversial product", Journal of Business Research, Vol. 57 No. 10, pp. 1189-1198.

Yoo, B. and Lee, S.-H. (2012), "Asymmetrical effects of past experiences with genuine fashion luxury brands and their counterfeits on purchase intention of each", Journal of Business Research, Vol. 65 No. 10, pp. 1507-1515.

Zhan, L., Sharma, P. and Chan, R.Y.K. (2015), "Using Spotlight Effect to Curb Counterfeit Consumption - An Experimental Investigation", Marketing Intelligence \& Planning, Vol. 33 No. 4, pp. 556-574. 
Figure 1 - Conceptual framework and hypotheses (H1-H9)

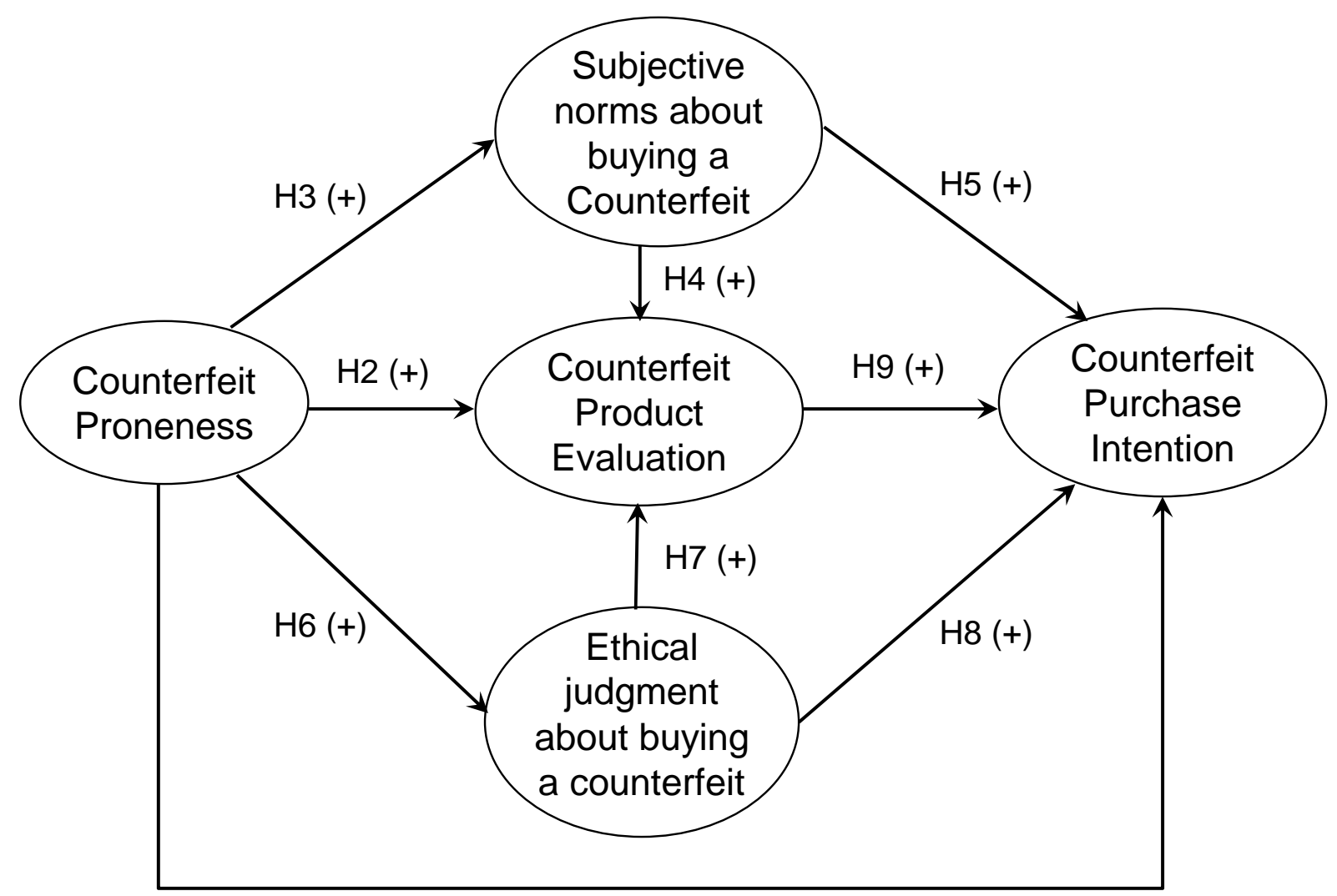

H1 (+) 
Table 1 - Sample composition (demographics)

\begin{tabular}{|c|c|c|c|c|c|}
\hline \multirow[b]{2}{*}{ Demographics } & \multirow{2}{*}{$\begin{array}{l}\text { Overall } \\
(\mathrm{N}=380)\end{array}$} & \multicolumn{4}{|c|}{ Product Categories } \\
\hline & & $\begin{array}{r}\text { Watch } \\
(\mathrm{N}=69) \\
\end{array}$ & $\begin{array}{c}\text { Software } \\
(\mathrm{N}=107)\end{array}$ & $\begin{array}{c}\text { DVD } \\
(\mathrm{N}=124)\end{array}$ & $\begin{array}{c}\text { Backpack } \\
(\mathbf{N}=\mathbf{8 0})\end{array}$ \\
\hline \multicolumn{6}{|l|}{ Gender } \\
\hline Female & $185(49 \%)$ & $39(57 \%)$ & $50(47 \%)$ & $55(44 \%)$ & $41(51 \%)$ \\
\hline Male & $195(51 \%)$ & $30(43 \%)$ & $57(53 \%)$ & $69(56 \%)$ & $39(49 \%)$ \\
\hline \multicolumn{6}{|l|}{ Age } \\
\hline$\leq 20$ & $119(31 \%)$ & $15(22 \%)$ & $49(45 \%)$ & $38(30 \%)$ & $17(21 \%)$ \\
\hline $21-30$ & $163(43 \%)$ & $21(31 \%)$ & $32(30 \%)$ & $59(47 \%)$ & $51(63 \%)$ \\
\hline $31-40$ & $54(14 \%)$ & $12(17 \%)$ & $12(11 \%)$ & $23(19 \%)$ & $7(9 \%)$ \\
\hline $41-50$ & $29(8 \%)$ & $18(26 \%)$ & $6(6 \%)$ & $2(2 \%)$ & $3(4 \%)$ \\
\hline$>50$ & $7(2 \%)$ & $2(3 \%)$ & $1(1 \%)$ & $2(2 \%)$ & $2(3 \%)$ \\
\hline Missing & $8(2 \%)$ & $1(1 \%)$ & $7(7 \%)$ & $0(0 \%)$ & $0(0 \%)$ \\
\hline \multicolumn{6}{|l|}{ Education level } \\
\hline High school or less & $131(34 \%)$ & $37(54 \%)$ & $37(35 \%)$ & $38(31 \%)$ & $19(24 \%)$ \\
\hline College/University & $178(47 \%)$ & $21(31 \%)$ & $45(42 \%)$ & $68(55 \%)$ & $44(55 \%)$ \\
\hline Postgraduate degree & $29(8 \%)$ & $4(6 \%)$ & $14(13 \%)$ & $7(5 \%)$ & $4(5 \%)$ \\
\hline Others & $42(11 \%)$ & $6(9 \%)$ & $11(10 \%)$ & $11(9 \%)$ & $13(16 \%)$ \\
\hline \multicolumn{6}{|l|}{ Occupation } \\
\hline Blue Collar & $29(8 \%)$ & $5(7 \%)$ & $10(9 \%)$ & $9(7 \%)$ & $5(6 \%)$ \\
\hline White Collar & $152(40 \%)$ & $37(54 \%)$ & $51(48 \%)$ & $44(35 \%)$ & $20(25 \%)$ \\
\hline Students & $145(38 \%)$ & $21(30 \%)$ & $28(26 \%)$ & $59(48 \%)$ & $37(46 \%)$ \\
\hline Others & $54(14 \%)$ & $6(9 \%)$ & $18(17 \%)$ & $12(10 \%)$ & $18(23 \%)$ \\
\hline \multicolumn{6}{|l|}{ Purchase } \\
\hline \multicolumn{6}{|l|}{$\begin{array}{l}\text { Frequency } \\
\text { (Past } 3 \text { Months) }\end{array}$} \\
\hline None & 237 (62\%) & $41(60 \%)$ & $52(48 \%)$ & $81(65 \%)$ & $63(79 \%)$ \\
\hline 1-2 Times & $114(30 \%)$ & $25(36 \%)$ & $38(36 \%)$ & $36(29 \%)$ & $15(18 \%)$ \\
\hline 3-5 Times & $20(5 \%)$ & $2(3 \%)$ & $10(9 \%)$ & $6(5 \%)$ & $2(3 \%)$ \\
\hline 6-10 Times & $6(2 \%)$ & $0(0 \%)$ & $5(5 \%)$ & $1(1 \%)$ & $0(0 \%)$ \\
\hline$>10$ Times & $3(1 \%)$ & $1(1 \%)$ & $2(2 \%)$ & $0(0 \%)$ & $0(0 \%)$ \\
\hline
\end{tabular}


Table 2 - Scale items (psychometric properties)

\begin{tabular}{|c|c|c|c|c|}
\hline Scale Items (Psychometric Properties) & $\lambda$ & $\alpha$ & $M$ & $S D$ \\
\hline \multicolumn{5}{|l|}{ Counterfeit Proneness } \\
\hline 1. Buying counterfeit products makes me feel good. & .80 & .64 & 4.13 & 1.45 \\
\hline 2. I feel excited when buying counterfeit products. & .78 & .60 & 3.79 & 1.45 \\
\hline $\begin{array}{l}\text { 3. When I buy counterfeit products, I feel that I am } \\
\text { getting a good deal. }\end{array}$ & .79 & .63 & 3.97 & 1.55 \\
\hline $\begin{array}{l}\text { 4. I enjoy buying counterfeits, regardless of the } \\
\text { money I save by doing so. }\end{array}$ & .75 & .61 & 3.73 & 1.51 \\
\hline $\begin{array}{l}\text { 5. Many of the branded products that I have are } \\
\text { counterfeits. }\end{array}$ & .77 & .62 & 3.55 & 1.54 \\
\hline $\begin{array}{l}\text { 6. Counterfeits enable me to own brands that I } \\
\text { normally would not buy. }\end{array}$ & .73 & .58 & 3.88 & 1.65 \\
\hline \multicolumn{5}{|l|}{ Subjective Norm } \\
\hline $\begin{array}{l}\text { 7. I think no one will mind if I buy this fake } \\
<\text { Product }>\text {. }\end{array}$ & .84 & .71 & 4.44 & 1.54 \\
\hline $\begin{array}{l}\text { 8. I think everyone will consider it a smart decision } \\
\text { if I buy this fake < product }>\text {. }\end{array}$ & .83 & .69 & 4.43 & 1.50 \\
\hline $\begin{array}{l}\text { 9. I think everyone would like me to buy this fake } \\
<\text { Product }>\text {. }\end{array}$ & .85 & .73 & 4.33 & 1.52 \\
\hline \multicolumn{5}{|l|}{ Ethical Judgments } \\
\hline $\begin{array}{l}\text { 10. I think buying this fake }<\text { Product }>\text { would be } \\
\text { immoral. * }\end{array}$ & .75 & .62 & 4.82 & 1.45 \\
\hline $\begin{array}{l}\text { 11. I think buying this fake }<\text { Product }>\text { would be } \\
\text { unethical. * }\end{array}$ & .73 & .53 & 4.87 & 1.42 \\
\hline $\begin{array}{l}\text { 12. I think buying this fake }<\text { Product }>\text { would be } \\
\text { illegal. * }\end{array}$ & .80 & .64 & 4.59 & 1.50 \\
\hline $\begin{array}{l}\text { 13. I think buying this fake }<\text { Product }>\text { would be } \\
\text { wrong. * }\end{array}$ & .86 & .74 & 4.76 & 1.41 \\
\hline \multicolumn{5}{|l|}{ Product Evaluation } \\
\hline $\begin{array}{l}\text { 14. I think this fake }<\text { Product }>\text { looks as good as a } \\
\text { genuine }<\text { Product }>\text {. }\end{array}$ & .80 & .64 & 4.80 & 1.53 \\
\hline $\begin{array}{l}\text { 15. I think this fake }<\text { Product }>\text { will work as good as a } \\
\text { genuine }<\text { Product }>\text {. }\end{array}$ & .88 & .78 & 4.88 & 1.55 \\
\hline $\begin{array}{l}\text { 16. I think this fake }<\text { Product }>\text { will last as long as a } \\
\text { genuine }<\text { Product }>\text {. }\end{array}$ & .85 & .71 & 4.69 & 1.60 \\
\hline \multicolumn{5}{|l|}{ Purchase Intentions } \\
\hline 17. I would not mind buying this fake $<$ Product $>$. & .78 & .61 & 4.45 & 1.57 \\
\hline $\begin{array}{l}\text { 18. I think buying this fake }<\text { Product }>\text { would be a } \\
\text { smart decision. }\end{array}$ & .87 & .77 & 4.36 & 1.48 \\
\hline 19. I would love to buy this fake $<$ Product $>$. & .84 & .72 & 4.52 & 1.40 \\
\hline $\begin{array}{l}\text { 20. I will have no hesitation in buying this fake } \\
<\text { Product }>\text {. }\end{array}$ & .82 & .67 & 4.48 & 1.40 \\
\hline
\end{tabular}

Note: $\lambda$ : Standardized factor loadings, $\alpha$ : Squared multiple correlations, $M=$ Mean, $S D=$ Standard deviation * Reverse-worded items 
Table 3 - Correlations matrix

\begin{tabular}{lccccccc}
\hline Construct & $\boldsymbol{M}$ & $\boldsymbol{S D}$ & $\boldsymbol{C F P}$ & $\boldsymbol{E T H}$ & $\boldsymbol{S U B}$ & $\boldsymbol{C P E}$ & $\boldsymbol{C P I}$ \\
\hline Counterfeit Proneness (CFP) & 3.84 & 1.52 & - & & & & \\
Subjective Norms (SUB) & 4.40 & 1.49 & .49 & - & & & \\
Ethical Judgment (ETH) & 4.76 & 1.44 & .29 & .31 & - & & \\
Counterfeit Product Evaluation (CPE) & 4.79 & 1.53 & .33 & .49 & .40 & - & \\
Counterfeit Purchase Intentions (CPI) & 4.45 & 1.48 & .45 & .56 & .40 & .63 & - \\
\hline Average Variance Extracted (AVE) & - & - & .59 & .70 & .62 & .71 & .69 \\
Composite Reliability (CR) & - & - & .82 & .89 & .84 & .90 & .88 \\
\hline
\end{tabular}

Note: All correlation coefficients are significant at $p<.001$ level 
Table 4 - Structural model (path coefficients)

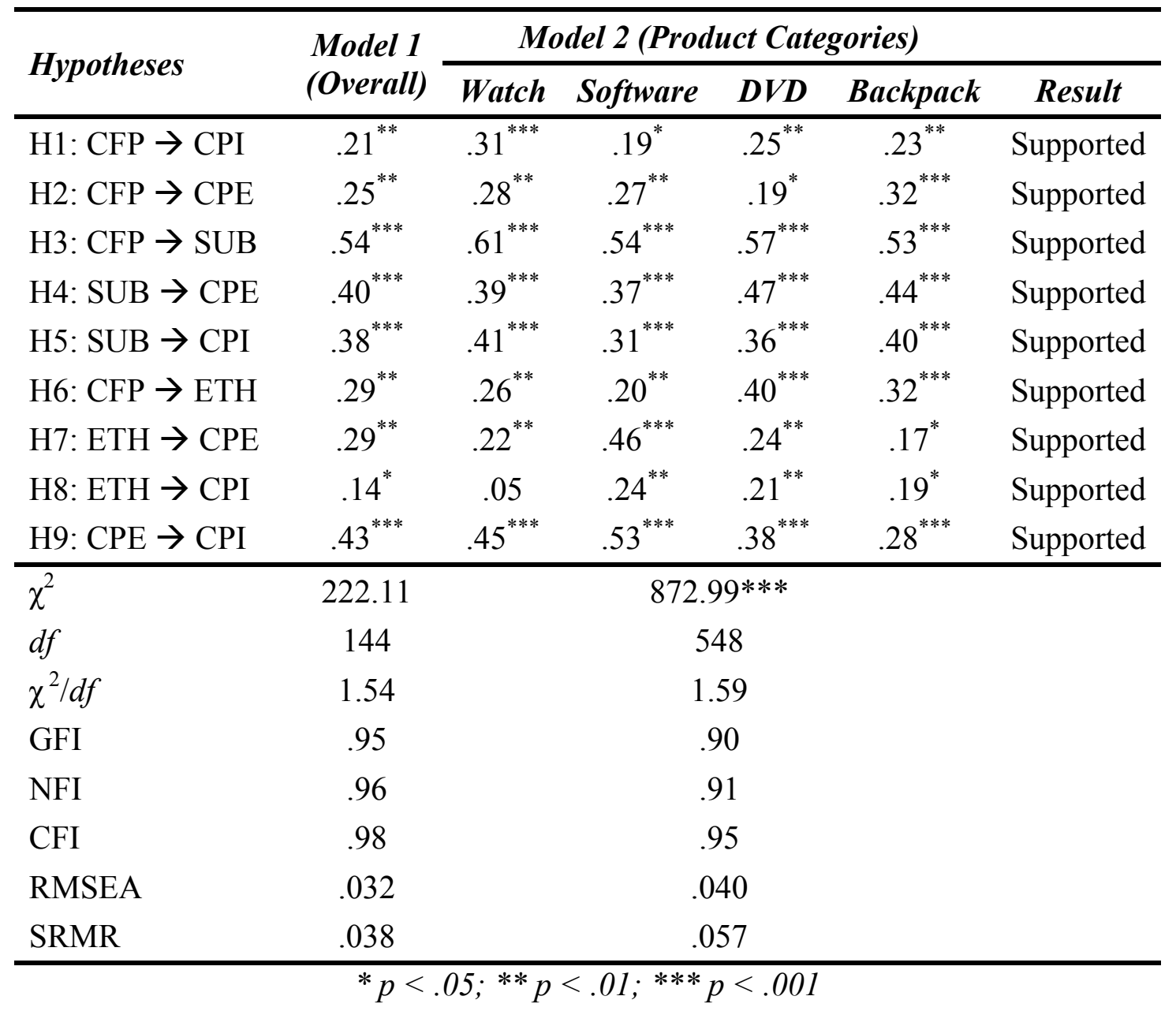

